\title{
Mathematical model of uptake and metabolism of arsenic(III) in human hepatocytes - Incorporation of cellular antioxidant response and threshold- dependent behavior
}

\author{
Spyros K Stamatelos ${ }^{1,2}$, Christopher J Brinkerhoff ${ }^{1}$, Sastry S Isukapalli ${ }^{1}$ Panos G Georgopoulos ${ }^{1 *}$
}

\begin{abstract}
Background: Arsenic is an environmental pollutant, potent human toxicant, and oxidative stress agent with a multiplicity of health effects associated with both acute and chronic exposures. A semi-mechanistic cellular-level toxicokinetic (TK) model was developed in order to describe the uptake, biotransformation and clearance of arsenical species in human hepatocytes. Notable features of this model are the incorporation of arsenic-glutathione complex formation and a "switch-like" formulation to describe the antioxidant response of hepatocytes to arsenic exposure.

Results: The cellular-level TK model applies mass action kinetics in order to predict the concentrations of trivalent and pentavalent arsenicals in hepatocytes. The model simulates uptake of arsenite (iAs') via aquaporin isozymes 9 (AQP9s), glutathione (GSH) conjugation, methylation by arsenic methyltransferase (AS3MT), efflux through multidrug resistant proteins (MRPs) and the induced antioxidant response via thioredoxin reductase (TR) activity. The model was parameterized by optimization of model estimates for arsenite (iAs'II), monomethylated (MMA) and dimethylated (DMA) arsenicals concentrations with time-course experimental data in human hepatocytes for a time span of 48 hours, and dose-response data at 24 hours for a range of arsenite concentrations from 0.1 to $10 \mu \mathrm{M}$. Global sensitivity analysis of the model showed that at low doses the transport parameters had a dominant role, whereas at higher doses the biotransformation parameters were the most significant. A parametric comparison of the TK model with an analogous model developed for rat hepatocytes from the literature demonstrated that the biotransformation of arsenite (e.g. GSH conjugation) has a large role in explaining the variation in methylation between rats and humans.

Conclusions: The cellular-level TK model captures the temporal modes of arsenical accumulation in human hepatocytes. It highlighted the key biological processes that influence arsenic metabolism by explicitly modelling the metabolic network of GSH-adducts formation. The parametric comparison with the TK model developed for rats suggests that the variability in GSH conjugation could have an important role in inter-species variability of arsenical methylation. The TK model can be incorporated into larger-scale physiologically based toxicokinetic (PBTK) models of arsenic for improving the estimates of PBTK model parameters.
\end{abstract}

\footnotetext{
* Correspondence: panosg@ccl.rutgers.edu

${ }^{1}$ Environmental and Occupational Health Sciences Institute (EOHSI) a joint institute of UMDNJ-Robert Wood Johnson Medical School and Rutgers

University 170 Frelinghuysen Rd, Piscataway, NJ 08854 USA

Full list of author information is available at the end of the article
} 


\section{Background}

Arsenic is a naturally occurring metalloid, abundant in the earth's crust and a component of more than 245 minerals [1]. Exposure to arsenic has been associated with cancers of the liver, bladder, skin and lung $[2,3]$. Epidemiological studies in Taiwan, Bangladesh and India have reported adverse health effects associated with chronic arsenic exposure including; chronic obstructive pulmonary disease, non-cirrhotic portal fibrosis, hypertension and ischeamic heart disease [4]. The risk of developing serious diseases from chronic exposure to inorganic arsenic in drinking water prompted the US Environmental Protection Agency (EPA) to lower the maximum contamination level (MCL) for arsenic in drinking water to $10 \mathrm{ppb}$ [5].

There are two biologically important arsenic valence states: arsenite $\left(\mathrm{As}(\mathrm{OH})^{3}, \mathrm{iAs}^{\mathrm{III}}\right)$ and arsenate $\left(\mathrm{AsO}(\mathrm{OH})^{3}\right.$, $\mathrm{iAs}^{\mathrm{V}}$ ). Inorganic arsenic in water is largely in the form of arsenate; it is negatively charged at physiological $\mathrm{pH}$ and slowly taken up by cells [6]. Arsenate is rapidly converted to arsenite in vivo [7] which is taken up by cells much more quickly than arsenate [8]. Methylation of arsenicals facilitates their excretion from the cell and therefore was long considered a detoxification process, but recent evidence indicates that monomethylated (MMA) and dimethylated (DMA) arsenicals have many toxic effects including increased oxidative stress [9], chromosomal aberrations (CA), and oxidative DNA damage [10-12]. In hepatocytes, trivalent monomethylated arsenicals $\left(\mathrm{MMA}^{\mathrm{III}}\right)$ inhibit the activity of thioredoxin reductase (TR), which is a critical antioxidant enzyme controlling the cellular redox balance $[13,14]$.

Uptake and efflux of arsenicals occur primarily through transporter proteins. Uptake of iAs ${ }^{\mathrm{III}}$ in hepatocytes and efflux of $\mathrm{MMA}^{\mathrm{III}}$ to blood take place through aquaporin isozymes 9 (AQP9), a family of membrane-spanning proteins that facilitate movement of solutes down their concentration gradient. AQP9 channels are expressed at high concentrations in liver cells and have been shown to transport iAs ${ }^{\mathrm{III}}$ when expressed both in Saccharomyces cerevisiae (yeast) and in Xenopus oocytes [15-17]. Another class of transmembrane proteins facilitating the transport of iAs ${ }^{\mathrm{III}}$ and MMA ${ }^{\mathrm{III}}$ across the cellular membrane of hepatocytes is glucose transporters and especially GLUT2 which is highly expressed in the liver $[18,19]$. Glutathione conjugated arsenicals are exported to the extracellular space via multidrug resistant proteins (MRPs) and multidrug resistant P-glycoproteins (PGPs)which are ATPbinding cassette $(\mathrm{ABC})$ transporters that export solutes against their concentration gradient [19-21].

Methylation of inorganic arsenic takes place primarily in the liver and specifically in hepatocytes via enzymatic catalysis by arsenic methyltransferase (AS3MT), previously known as Cyt19, producing both mono- and dimethylated arsenicals [22-25]. Two biochemical pathways have been proposed for methylation of arsenates with a key difference in the substrate for AS3MT methylation: (a) a classical process of alternating steps of reduction and oxidative methylation where iAs ${ }^{\mathrm{III}}$ and $\mathrm{MMA}^{\mathrm{III}}$ are the substrates and the methylation can happen in the presence or absence of GSH [26] and (b) a process of GSH conjugation and reductive methylation where thiol-bound arsenicals (arsenic triglutathione - ATG, monomethylarsenic diglutathione - MADG) are the substrates [27,28]. GSH has a stimulatory role in both methylation pathways either as a reductant or in direct conjugation with arsenicals [29].

Arsenic activates the redox sensitive transcription factor Nuclear Factor -E2- related factor 2 (Nrf2) causing its increased nuclear translocation and Nrf2 binding to the Antioxidant Response Element (ARE) [30,31]. Arsenic activates Nrf2 in a different manner when compared to other compounds such as sulforaphane (SF) and tert-butylhydroquinone (tBHQ) enhancing the interaction of specific subunits of the E3 ubiquitin ligase [32]. It has been suggested that hepatocytes exhibit an "on-switch" antioxidant behavior when exposed to increasing arsenic doses [33], possibly a result of this Nrf2 activation.

In this study, a cellular-level semi-mechanistic TK model was developed for predicting intra-cellular concentrations of different arsenicals (trivalent and pentavalent) in hepatocytes. Currently, the only published cellular-level TK model for the uptake, biotransformation and efflux of arsenicals is the Easterling et al. [34] model schematically shown in Figure 1; they demonstrated the relative importance of transport processes affecting the accumulation of arsenicals in rat hepatocytes [34]. However, a TK model for humans is needed since the inherent variation of arsenic metabolic capacity across various organisms complicates the extrapolation of rat TK model to humans. Therefore, the mathematical model presented here was developed for humans and parameterized based on data from human hepatocytes.

\section{Methods}

The human TK model applies mass action kinetics in order to predict the concentrations of trivalent and pentavalent arsenicals including arsenite $\left(\mathrm{iAs}^{\mathrm{III}}\right.$ ), monomethylated (MMA), and dimethylated arsenicals (DMA) in human hepatocytes. This TK model takes into account processes such as influx, efflux, methylation, oxidation and glutathione conjugation of arsenicals. Moreover, it accounts for induced cellular antioxidant response due to arsenic exposure through a "switch-like" mechanism that alters the model response above a specific threshold concentration [35]. 


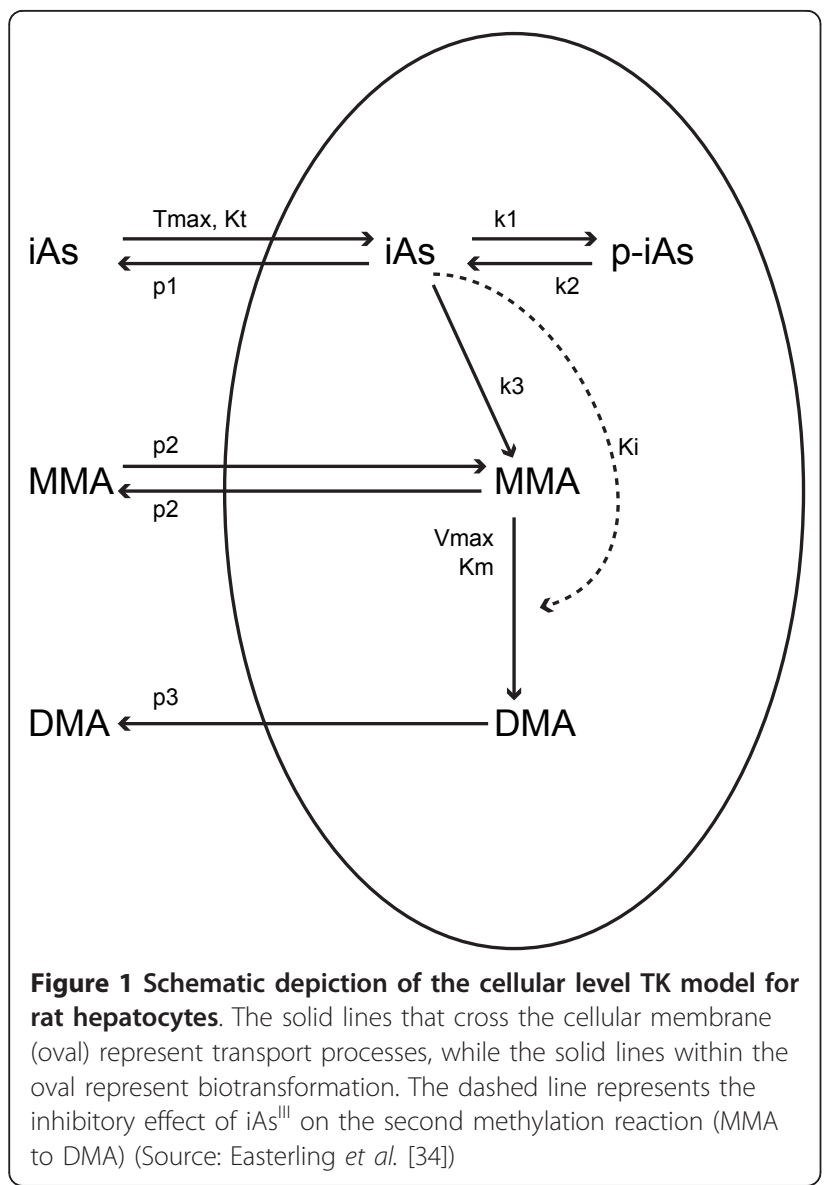

This model has been compared with the Easterling et al. model [34], in terms of the ability to fit to data of arsenic retention and methylation in human hepatocytes. This comparison aims to highlight the advantages of developing biologically relevant TK models based on data acquired from human cells. Further comparison of these two models in terms of their estimated parameter values aim to study the major intracellular kinetic processes that contribute to the differences in metabolism between humans and rats.

\section{Model Development}

The semi-mechanistic TK model describes arsenic transport across the cellular membrane and arsenic metabolism in hepatocytes according to the metabolic reaction cascade proposed by Hayakawa et al. [27] (Figure 2). Figure 3 presents a schematic depiction of the constituents of the TK model that are also explained in Table 1. These constituents include chemical species and enzymes, and the interactions among them. Fundamental assumptions made in the formulation of the TK model are:

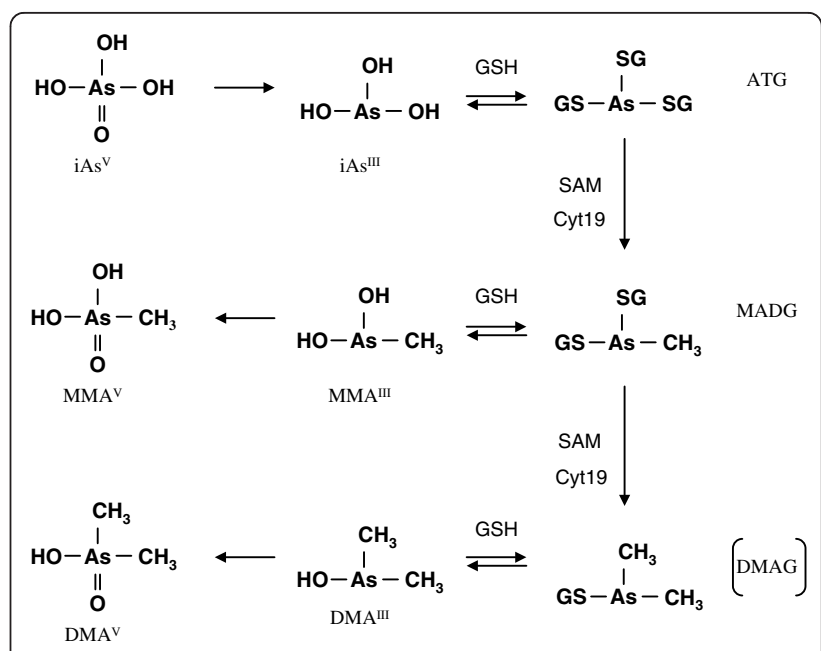

Figure 2 A new metabolic pathway of inorganic arsenic biotransformation via arsenic-GSH complexes formation. This pathway includes two separate branches of arsenic

biotransformation: MADG $\rightarrow \mathrm{MMA}^{\mathrm{III}} \rightarrow \mathrm{MMA}^{\mathrm{V}}$ and MADG $\rightarrow$ DMAG $\rightarrow \mathrm{DMA}^{\mathrm{III}} \rightarrow \mathrm{DMA}^{\mathrm{V}}$ (Source: Hayakaya et al. [27]).

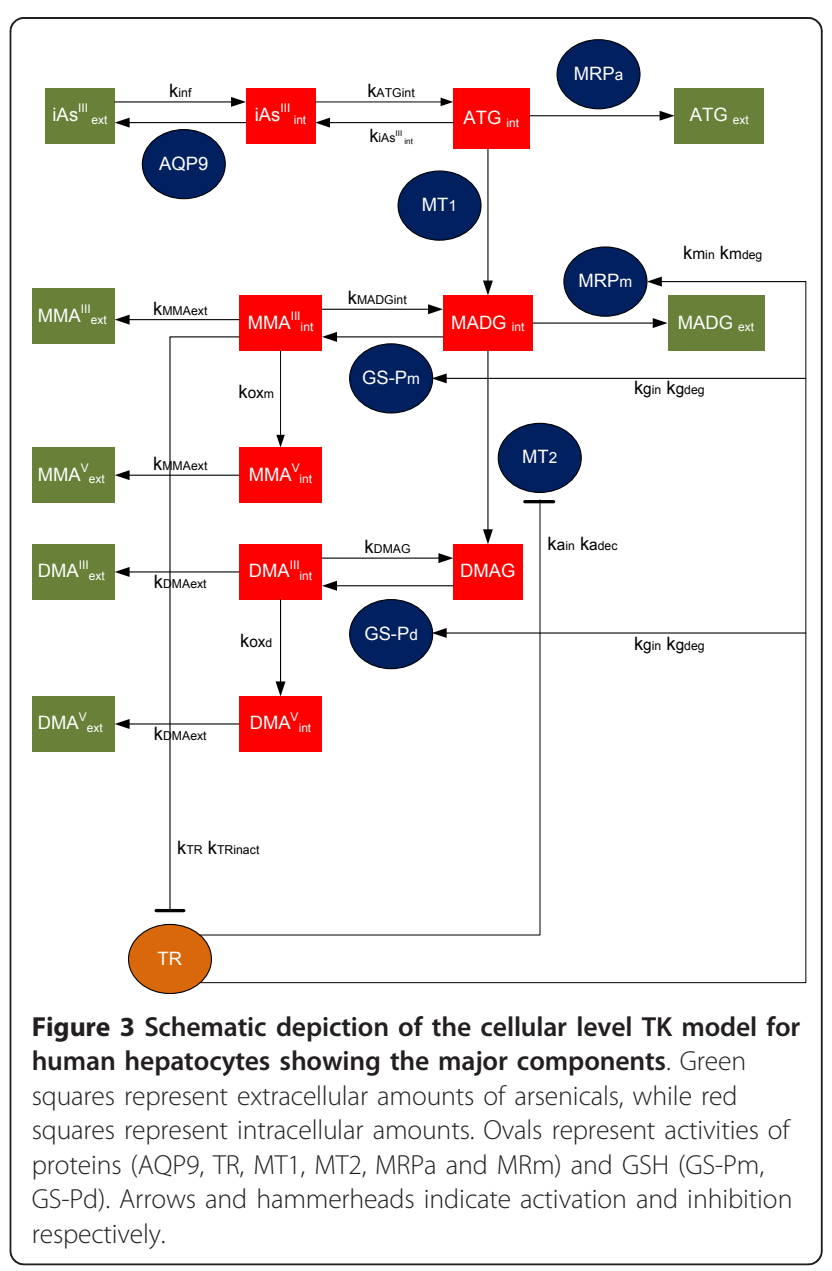


Table 1 Optimized parameter values of the TK model along with the corresponding process they describe

\begin{tabular}{|c|c|c|c|c|}
\hline Notation & Parameter & Value & Units & Description \\
\hline 1 & $\mathrm{k}_{\text {ATG int }}$ & 0.25 & $1 / \min$ & Rate of production of ATG \\
\hline 2 & $\mathrm{k}_{\text {MADG int }}$ & 90 & $1 / \min$ & Rate of production of MADG \\
\hline 3 & $k_{D M A G}$ & 0.0122 & $1 / \min$ & Rate of production of DMAG \\
\hline 4 & $\mathrm{k}_{\mathrm{oxd}}$ & 33.254 & $1 / \min$ & Rate of oxidation of DMA ${ }^{\text {III }}$ \\
\hline 5 & $\mathrm{k}_{\mathrm{oxm}}$ & 0.2375 & $1 /$ min & Rate of oxidation of MMA $\mathrm{MAI}^{\mathrm{II}}$ \\
\hline 6 & $\mathrm{k}_{\mathrm{iAs}}^{\mathrm{III}}$ int & 320 & $1 / \mathrm{min}$ & Rate of production of iAs ${ }^{\prime \prime \prime}$ \\
\hline 7 & $\mathrm{k}_{\mathrm{MMA}}{ }^{\mathrm{III}}$ int & 1200 & $1 / \min$ & Rate of production of MMA III \\
\hline 8 & $\mathrm{n}_{3}$ & 8 & - & Hill coefficient of inhibition of MMA"I production \\
\hline 9 & $\mathrm{Kd}_{3}$ & 12.94 & $\mu \mathrm{M}$ & Dissociation constant of inhibition of MMA ${ }^{\text {III }}$ \\
\hline 10 & $f_{G S H m}$ & 0.992 & - & Coefficient of inhibition of MADG hydrolysis \\
\hline 11 & $\mathrm{~kg}_{\mathrm{in}}$ & 704.96 & $1 / \min$ & Rate of GSH production increase \\
\hline 12 & $\mathrm{k}_{\mathrm{DMA}}{ }^{\mathrm{II}}$ int & 0.8472 & $1 / \min$ & Rate of production of DMA ${ }^{\text {III }}$ \\
\hline 13 & $f_{G S H d}$ & 0.9988 & - & Coefficient of inhibition of DMAG hydrolysis \\
\hline 14 & $V_{\max }$ & 1.237 & $\mathrm{pmol} / \mathrm{min}$ & Maximal rate of MADG efflux \\
\hline 15 & $\mathrm{Km}_{\mathrm{t} 2}$ & 19.47 & $\mu \mathrm{M}$ & Half saturation constant of MADG efflux \\
\hline 16 & $\mathrm{~km}_{\text {in }}$ & 512.27 & $1 / \min$ & Rate of upregulation of MRP \\
\hline 17 & $k_{s 5}$ & 4.26 & $1 / \mathrm{min}$ & Steady state rate of efflux of iAs ${ }^{\text {III }}$ \\
\hline 18 & $\tau_{\mathrm{e}}$ & 10 & $\min$ & Time constant of AQP9 inactivation \\
\hline 19 & $k_{0}$ & 4.2 & $1 / \mathrm{min}$ & Initial rate of efflux of iAs ${ }^{\text {III }}$ \\
\hline 20 & $k_{\text {inf }}$ & 1.613 & $1 / \mathrm{min}$ & Influx of iAs'III \\
\hline 21 & $\mathrm{k}_{\text {MMAext }}$ & 0.0006 & $1 / \min$ & Rate of efflux of MMA \\
\hline 22 & $f_{m}$ & 0.2 & - & Coefficient of efflux of MMA \\
\hline 23 & $\mathrm{Vmax}_{\mathrm{t} 1}$ & 0.35 & $\mathrm{pmol} / \mathrm{min}$ & Maximal rate of ATG efflux \\
\hline 24 & $\mathrm{Km}_{\mathrm{t} 1}$ & 2.3 & $\mu \mathrm{M}$ & Half saturation constant of ATG efflux \\
\hline 25 & $\mathrm{k}_{\text {DMAext }}$ & 0.002 & $1 / \min$ & Rate of efflux of DMA \\
\hline 26 & $f_{d}$ & 3 & - & Coefficient of efflux of DMA \\
\hline 27 & $\operatorname{Vmax}_{m}$ & 50 & $\mathrm{pmol} / \mathrm{min}$ & Maximal rate of ATG methylation \\
\hline 28 & $\mathrm{Km}_{\mathrm{m}}$ & 9.32 & $\mu \mathrm{M}$ & Half saturation constant of ATG methylation \\
\hline 29 & $\mathrm{n}_{1}$ & 1.22 & - & Hill coefficient of ATG methylation \\
\hline 30 & $\mathrm{Kd}_{1}$ & 0.315 & $\mu \mathrm{M}$ & Dissociation constant of ATG methylation \\
\hline 31 & $\mathrm{~K}_{\mathrm{im}}$ & 1.53 & $\mu \mathrm{M}$ & Inhibition constant of ATG methylation \\
\hline 32 & $K_{\text {id }}$ & 1 & $\mu \mathrm{M}$ & Inhibition constant of MADG methylation \\
\hline 33 & $\operatorname{Vmax}_{d}$ & 8 & $\mathrm{pmol} / \mathrm{min}$ & Maximal rate of MADG methylation \\
\hline 34 & $\mathrm{Km}_{\mathrm{d}}$ & 0.034 & $\mu \mathrm{M}$ & Half saturation constant of MADG methylation \\
\hline 35 & $\mathrm{n}_{2}$ & 1.83 & - & Hill coefficient of MADG methylation \\
\hline 36 & $\mathrm{Kd}_{2}$ & 2.33 & $\mu \mathrm{M}$ & Dissociation constant of MADG methylation \\
\hline 37 & $k a_{\text {in }}$ & 1.64 & $1 / \min$ & Rate of AS3MT efficiency increase \\
\hline 38 & $f_{A}$ & 50 & - & Coefficient of MADG methylation inactivation \\
\hline 39 & $\mathrm{k}_{\mathrm{TR}}$ & 0.99 & $1 / \min$ & Rate of TR signaling \\
\hline 40 & $k_{\text {TRinact }}$ & 987.13 & $1 / \min$ & Rate of TR inactivation \\
\hline 41 & $T R_{C}$ & 15 & - & Constant of TR inactivation \\
\hline 42 & $\mathrm{~N}$ & 1.75 & - & Hill coefficient of TR inactivation \\
\hline 43 & $\mathrm{TR}_{0}$ & 9.27 & $1 / \min$ & Steady state value of TR activity \\
\hline
\end{tabular}


1) Arsenite influx across the cellular membrane pores is governed by their electrochemical potential, and can be described through an ion channel conductance-based formulation.

2) The oxidative stress mediated response of hepatocytes to arsenite exposure exhibits a "switch-like" behavior, and the upregulation of enzyme activities can be described through an approximate step function at a threshold concentration.

3) The methylation reactions are influenced by cooperativity phenomena as well as substrate inhibition, and can be described through a hybrid approach of Hill and Michaelis-Menten kinetics.

4) The GSH-bound hydrolysis and clearance of methylated arsenicals exhibit a threshold-dependent behavior, and can be described using a sigmoidal function.

5) Concentrations of arsenicals are uniform within the hepatocytes as well as the extracellular medium

6) All hepatocytes in the system have identical properties, are uniformly distributed in the medium, and are exposed to the same extracellular concentrations of arsenicals.

Uptake of arsenite by hepatocytes via AQP9s [36] is governed by their electrochemical potential across the cellular membrane (for simplicity we refer to AQP9s as being the ensemble of the activity of both AQP9 and GLUT2 channels). The conductance-based formulation for ion channels proposed in the Hodgkin-Huxley model [37] is used here to describe the regulation of arsenite flux by AQP9s (Equations 1-2). Specifically, the inactivation of AQP9 subunit gates during $\mathrm{iAs}{ }^{\mathrm{III}}$ influx is described by Equation 1b, which expresses the increased probability of these gates closing as more transport across the gates occurs.

$$
\begin{aligned}
& \frac{\mathrm{d}\left(\mathrm{iAs}^{\mathrm{III}}\right)_{\mathrm{int}}}{\mathrm{dt}}=\mathrm{k}_{\mathrm{inf}} \times\left(\mathrm{iAs}^{\mathrm{III}}\right)_{\mathrm{ext}}-\mathrm{AQP9} \times\left(\mathrm{iAs}{ }^{\mathrm{III}}\right)_{\mathrm{int}} \\
& -\mathrm{k}_{\mathrm{ATG}_{\text {int }}} \times\left(\mathrm{iAs}^{\mathrm{III}}\right)_{\mathrm{int}}+\mathrm{k}_{\mathrm{iAs}} \mathrm{III}_{\text {int }} \times(\mathrm{ATG})_{\mathrm{int}} \\
& \mathrm{AQP9}=\left[\mathrm{k}_{0}+\left(\mathrm{k}_{\mathrm{SS}}-\mathrm{k}_{0}\right) \times\left(1-\mathrm{e}^{-\frac{\mathrm{t}}{\tau_{\mathrm{e}}}}\right)\right] \\
& \frac{\mathrm{d}\left(\mathrm{iAs}^{\mathrm{III}}\right)_{\mathrm{ext}}}{\mathrm{dt}}=\mathrm{AQP9} \times\left(\mathrm{iAs}^{\mathrm{III}}\right)_{\mathrm{int}}-\mathrm{k}_{\mathrm{inf}} \times\left(\mathrm{iAs}^{\mathrm{III}}\right)_{\mathrm{ext}}
\end{aligned}
$$

Where, $\mathrm{k}_{\text {inf }}$ represents the mass transfer coefficient for influx of arsenite in hepatocytes; $\mathrm{k}_{\mathrm{ATG}_{\mathrm{int}}}$ represents the rate constant for arsenite conjugation with GSH to form ATG catalyzed by the Glutathione S-Transferase (GST) family of enzymes; $\mathrm{k}_{\mathrm{iAs}}{ }_{\text {int }}$ is the rate constant for hydrolysis of ATG (reciprocal to conjugation); $\mathrm{k}_{\mathrm{SS}}$ is the steady state rate constant for efflux of arsenite that is attained at long time periods; $\mathrm{k}_{0}$ is the rate constant describing the basal activity of AQP9; and $\tau_{\mathrm{e}}$ is the time constant governing the regulation of AQP9 gates.

Thioredoxin (Trx) Reductase (TR) is the enzyme that catalyzes the reduction of Trx. Trx is a critical antioxidant protein and an important reductant in the methylation of arsenic by AS3MT [38]. The inactivation of TR by MMA ${ }^{\mathrm{III}}$ leads to signals that account for two different phenomena: the induction of GSH and ABC transporters via a redox sensitive activation of the cellular antioxidant response Nrf2 nuclear receptor pathway $[14,39]$ and the decreased methylation capacity of AS3MT. In this study the main focus is on MRPs as an efflux mechanism of arsenicals since it has been reported that they are regulated by Nrf2 $[40,41]$. The inactivation is modeled using principles of indirect response model theory $[42,43]$ via the threshold-dependent parameter: $S=\frac{\left[\text { iAs }^{\mathrm{III}}\right]_{\text {init }}-\text { threshold }}{\text { threshold }}$. Parameter $S$ depends on the initial exposure concentration of arsenite, $\left(\mathrm{iAs}{ }^{\mathrm{III}}\right)_{\text {init }}$ and a threshold concentration. The value of $\mathrm{S}$ is zero when arsenite doses are below the threshold concentration, and gradually increases with greater arsenite doses. The following equations describe this reaction cascade:

$$
\begin{aligned}
& \frac{\mathrm{dTR}}{\mathrm{dt}}=\mathrm{k}_{\mathrm{TR}} \times\left(\mathrm{TR}_{0}-\mathrm{TR}\right)-\frac{\mathrm{s}}{\mathrm{TR}_{\mathrm{C}}} \\
& \times \mathrm{k}_{\mathrm{TR}_{\text {inact }}} \times \mathrm{H}_{\mathrm{TR}}
\end{aligned}
$$

$$
\mathrm{H}_{\mathrm{TR}}=\frac{\left[\mathrm{MMA}^{\mathrm{III}}\right]^{\mathrm{N}}}{\left(\mathrm{IC}_{\mathrm{TR}}\right)^{\mathrm{N}}+\left[\mathrm{MMA}^{\mathrm{III}}\right]^{\mathrm{N}}}
$$

$\frac{\mathrm{dGSH}}{\mathrm{dt}}=\mathrm{k}_{\mathrm{g}_{\mathrm{in}}} \times \frac{1}{\mathrm{TR}}-\mathrm{k}_{\mathrm{g}_{\mathrm{deg}}} \times \mathrm{GSH}$

$$
\mathrm{k}_{\mathrm{g}_{\text {deg }}}=\frac{\mathrm{k}_{\mathrm{g}_{\text {in }}}}{\mathrm{TR}_{0}}
$$

$$
\frac{\mathrm{dMRP}}{\mathrm{dt}}=\mathrm{k}_{\mathrm{m}_{\mathrm{in}}} \times \frac{1}{\mathrm{TR}}-\mathrm{k}_{\mathrm{m}_{\mathrm{deg}}} \times \mathrm{MRP}
$$

$$
\mathrm{k}_{\mathrm{m} \text { deg }}=\frac{\mathrm{k}_{\mathrm{m}_{\text {in }}}}{\mathrm{TR}_{0}}
$$




$$
\begin{aligned}
& \frac{\mathrm{dAS} 3 \mathrm{MT}}{\mathrm{dt}}=\mathrm{k}_{\mathrm{a}_{\mathrm{in}}} \times \mathrm{TR}-\mathrm{k}_{\mathrm{a}_{\mathrm{dec}}} \times \mathrm{AS} 3 \mathrm{MT} \\
& \mathrm{k}_{\mathrm{a}_{\mathrm{dec}}}=\mathrm{k}_{\mathrm{a}_{\text {in }}} \times \mathrm{TR}_{0}
\end{aligned}
$$

where, $\mathrm{k}_{\mathrm{TR}}$ is the first-order rate constant controlling the activity of $\mathrm{TR}$; $\mathrm{TR}_{0}$ is the baseline activity value of $\mathrm{TR} ; \mathrm{k}_{\mathrm{TR}_{\text {inact }}}$ is the first-order rate constant for $\mathrm{TR}$ inactivation; $\mathrm{TR}_{\mathrm{c}}$ is a dimensionless inactivation constant; $\mathrm{N}$ is the Hill coefficient for enzyme inactivation from $M M A^{I I I} ; \mathrm{k}_{\mathrm{g}_{\text {in }}}, \mathrm{k}_{\mathrm{m}_{\text {in }}}$ and $\mathrm{k}_{\mathrm{a}_{\text {in }}}$ are the rate constants governing of the activities of GSH, MRP and AS3MT, $k_{g_{d e g}}, k_{m_{d e g}}$ and $k_{a_{d e c}}$ are the corresponding first-order decay constants.

Methylation reactions of arsenic in the liver have been modeled in published cellular-level and whole-body PBTK models with classical Michaelis-Menten kinetics [34,44-46]. Alternatives include cooperativity models such as the classical Hill-type formulation and the more mechanistic Monod-Wyman-Changeux (MWC) model [47]. In preliminary analyses, these formulations were unable to explain the time course patterns of arsenic retention and methylation in human hepatocytes (results not shown). Therefore, an alternative, non-classical formulation was used in the TK model. In this model, the AS3MT is assumed to exhibit cooperativity and the methylation reaction rate is assumed to exhibit hysteretic sigmoidal behavior as per Frieden [48]. In this formulation, the cooperativity is described by a Hill-type formulation for $V_{\max }$ that is dependent on the total ATG present in the system. The formulation accounts for the constitutive influence of GSH in the methylation reaction cascade and its role in the increase of $\mathrm{V}_{\text {max }}$. Moreover this Hill-type formulation for $\mathrm{V}_{\max }$ accounts for a possible colocalization of thiol-containing proteins that interact with GSH (e.g. GSTP1), MRPs and AS3MT in hepatocytes. This colocalization would control not only the production and clearance of ATG but methylation activity as well $[49,50]$.

Previous studies have suggested that exposure of human hepatocytes to elevated doses of iAs ${ }^{\text {II }}$ (0.4 $4 \mu \mathrm{M})$ markedly reduced the production of DMAs while at the same time increased the yields of MMAs [51]. Therefore, it is assumed here that the AS3MT inactivation signal (Equation 6) affects only the second methylation reaction rate (Equation $8 \mathrm{a}$ ).

$$
\begin{aligned}
& \mathrm{MADG}_{\mathrm{ui}}=\mathrm{MT}_{1} \\
& \times \frac{[\mathrm{ATG}]_{\text {int }}}{1+\frac{[\mathrm{ATG}]_{\text {int }}}{\mathrm{Km}_{\mathrm{m}}} \times\left(1+\frac{[\mathrm{ATG}]_{\text {int }}}{\mathrm{K}_{\mathrm{im}}}\right)}
\end{aligned}
$$

$$
\begin{aligned}
& \mathrm{MT}_{1}=\frac{\left([\mathrm{ATG}]_{\text {int }}+[\mathrm{ATG}]_{\text {ext }}\right)^{\mathrm{n}_{1}}}{\left(\mathrm{Kd}_{1}\right)^{\mathrm{n}_{1}}+\left([\mathrm{ATG}]_{\mathrm{int}}+[\mathrm{ATG}]_{\text {ext }}\right)^{\mathrm{n}_{1}}} \\
& \times \frac{\mathrm{Vmax}_{\mathrm{m}}}{\mathrm{Km}_{\mathrm{m}}} \\
& \mathrm{DMAG}_{\mathrm{ui}}=\mathrm{MT}_{2} \\
& \times \frac{[\mathrm{MADG}]_{\text {int }}}{1+\frac{[\mathrm{MADG}]_{\text {int }}}{\mathrm{Km}_{\mathrm{d}}} \times\left(1+\frac{[\mathrm{ATG}]_{\text {int }}}{\mathrm{K}_{\mathrm{id}}}\right)} \\
& \mathrm{MT}_{2}=\frac{\mathrm{AS} 3 \mathrm{MT}}{\mathrm{f}_{\mathrm{A}} \times \tanh (\mathrm{S})+1} \\
& \times \frac{\left([\text { ATG }]_{\text {int }}+[\text { ATG }]_{\text {ext }}\right)^{n_{2}}}{\left(\mathrm{Kd}_{2}\right)^{\mathrm{n}_{2}}+\left([\mathrm{ATG}]_{\text {int }}+[\text { ATG }]_{\text {ext }}\right)^{\mathrm{n}_{2}}} \times \frac{\mathrm{Vmax}_{\mathrm{m}}}{\mathrm{Km}_{\mathrm{d}}}
\end{aligned}
$$

where, $M A D G_{u i}$ and $D M A G_{u i}$ are the rates of arsenic methylation for the first and second methylation reactions respectively. $V_{\max _{m}}$ and $V_{\max _{d}}$ are the maximal rates of the first and second methylation reactions respectively; $\mathrm{K}_{\mathrm{m}}$ and $\mathrm{K}_{\mathrm{m}_{\mathrm{d}}}$ are the half-saturation constants for the methylation reactions; $K_{i m}$ and $K_{i d}$ are the uncompetitive inhibition constants for the respective reactions $\mathrm{n}_{1}, \mathrm{n}_{2}$ are the Hill coefficients; $\mathrm{K}_{\mathrm{d}_{1}}$ and $\mathrm{K}_{\mathrm{d}_{2}}$ are the dissociation constants influencing the sigmoidal change in $V_{\max }$ and $V_{\max _{d}}$; and $f_{A}$ is a coefficient of the second methylation reaction inactivation.

MADG hydrolysis reaction is modeled using a "switch-like" formulation. For doses below the threshold, a Hill-type formulation is used (Equation 9b). Above the threshold concentration, the rates of hydrolysis of MADG and DMAG to MMA ${ }^{\text {III }}$ and DMA ${ }^{\text {III }}$, respectively, are assumed to be attenuated due to oxidative stress-induced GSH upregulation (Equations 9-10). On the other hand, this non-linear behavior may result in an increase or a decrease of GSH depending on the concentration of iAs ${ }^{\mathrm{II}}$ and the duration of exposure. The non-linear sigmoid function $\tanh (\mathrm{S})$ is used here to describe this "switch-like" behavior; this formula has been previously used [52] in a neurocomputational model to describe the non-linear threshold-dependent behavior of neuronal firing rate.

$$
\begin{aligned}
& \mathrm{HD}_{\mathrm{m}}=\left[1-\mathrm{f}_{\mathrm{GSH}_{\mathrm{m}}} \times \tanh (\mathrm{S})\right] \\
& \quad \times\left(1-\mathrm{H}_{\mathrm{GSH}}+\tanh (\mathrm{S}) \times \mathrm{H}_{\mathrm{GSH}}\right) \\
& \quad \times \mathrm{GS}-\mathrm{P}_{\mathrm{m}} \times(\mathrm{MADG})_{\mathrm{int}}
\end{aligned}
$$

$$
\text { GS-P } P_{m}=\frac{k_{{ }_{M M A}{ }^{\text {III }}}}{G S H}
$$




$$
\begin{aligned}
& \mathrm{H}_{\mathrm{GSH}}=\frac{\left([\mathrm{ATG}]_{\mathrm{int}}+[\mathrm{ATG}]_{\mathrm{ext}}\right)^{\mathrm{n}_{3}}}{\left(\mathrm{Kd}_{3}\right)^{\mathrm{n}_{3}}+\left([\mathrm{ATG}]_{\mathrm{int}}+[\mathrm{ATG}]_{\mathrm{ext}}\right)^{\mathrm{n}_{3}}} \\
& \mathrm{HD}_{\mathrm{d}}=\left[1-\mathrm{f}_{\mathrm{GSH}_{\mathrm{d}}} \times \tanh (\mathrm{S})\right] \times \mathrm{GS}-\mathrm{P}_{\mathrm{d}} \\
& \times(\mathrm{DMAG})_{\mathrm{int}} \\
& \text { GS-P } \mathrm{d}_{\mathrm{d}}=\frac{\mathrm{k}_{\mathrm{DMA}}{ }_{\text {int }}{ }_{\text {int }}}{\text { GSH }}
\end{aligned}
$$

where $\mathrm{HD}_{\mathrm{m}}$ and $\mathrm{HD}_{\mathrm{d}}$ are the rates of hydrolysis of MADG and DMAG respectively. $\mathrm{k}_{\mathrm{MMA}^{\mathrm{III}}}{ }_{\text {int }}$ is the reaction rate constant for MADG hydrolysis (MMA ${ }^{\mathrm{III}}$ production); $\mathrm{f}_{\mathrm{GSH}_{\mathrm{m}}}$ is the coefficient of inhibition of MADG hydrolysis; $\mathrm{n}_{3}$ and $\mathrm{K}_{\mathrm{d}_{3}}$ are the Hill coefficient and dissociation constant, respectively, for the inhibition term; $\mathrm{k}_{{ }_{\mathrm{DMA}}}{ }_{\text {III }}{ }_{\text {int }}$ is the reaction rate constant for DMAG hydrolysis (DMA ${ }^{\mathrm{III}}$ production); and $\mathrm{f}_{\mathrm{GSH}}$ is the coefficient of inhibition of DMAG hydrolysis.

Efflux of GSH (or protein) -bound arsenic adducts (ATG, MADG) is assumed to take place via multidrug resistant proteins (MRPs), and is described by classical Michaelis-Menten kinetics. Since MADG is a substrate in the dimethylation reaction (Equation 8a), its efflux rate is assumed to be affected by MRP levels [51].

$$
\begin{aligned}
& \frac{\mathrm{d}(\mathrm{ATG})_{\text {ext }}}{\mathrm{dt}}=\mathrm{MRP}_{\mathrm{a}} \times \frac{[\mathrm{ATG}]_{\text {int }}}{1+\frac{[\mathrm{ATG}]_{\text {int }}}{\mathrm{Km}_{\mathrm{t}_{1}}}} \\
& \mathrm{MRP}_{\mathrm{a}}=\frac{\mathrm{Vmax}_{\mathrm{t}_{1}}}{\mathrm{Km}_{\mathrm{t}_{1}}} \\
& \frac{\mathrm{d}(\mathrm{MADG})_{\mathrm{ext}}}{\mathrm{dt}}=\mathrm{MRP}_{\mathrm{m}} \times \frac{[\mathrm{MADG}]_{\text {int }}}{1+\frac{[\mathrm{MADG}]_{\text {int }}}{\mathrm{Km}_{\mathrm{t}_{2}}}} \\
& \mathrm{MRP_{ \textrm {m } }}=\mathrm{MRP} \times \frac{\mathrm{Vmax}_{\mathrm{t}_{2}}}{\mathrm{Km}_{\mathrm{t}_{2}}} \\
& \frac{\mathrm{d}\left(\mathrm{MMA}^{\mathrm{V}}\right)_{\mathrm{ext}}}{\mathrm{dt}}=\left[\left(\mathrm{f}_{\mathrm{m}^{-}}-1\right) \times \tanh (\mathrm{S})+1\right] \\
& \times \mathrm{k}_{\mathrm{MMA}} \times\left(\mathrm{MMA}^{\mathrm{V}}\right)_{\mathrm{int}}
\end{aligned}
$$

$$
\begin{aligned}
& \frac{\mathrm{d}\left(\mathrm{MMA}^{\mathrm{III}}\right)_{\text {ext }}}{\mathrm{dt}}=\left[\left(\mathrm{f}_{\mathrm{m}}-1\right) \times \tanh (\mathrm{S})+1\right] \\
& \times \mathrm{k}_{\mathrm{MMA}_{\text {ext }}} \times\left(\mathrm{MMA}^{\mathrm{III}}\right)_{\mathrm{int}} \\
& \frac{\mathrm{d}(\mathrm{DMA})^{\mathrm{V}}{ }_{\text {ext }}}{\mathrm{dt}}=\left[\left(\mathrm{f}_{\mathrm{d}}-1\right) \times \tanh (\mathrm{S})+1\right] \\
& \times \mathrm{k}_{\mathrm{DMA}} \times\left(\mathrm{DMA}^{\mathrm{V}}\right)_{\mathrm{int}} \times \\
& \frac{\mathrm{d}(\mathrm{DMA})^{\mathrm{III}}}{\mathrm{ext}}=\left[\left(\mathrm{f}_{\mathrm{d}}-1\right) \times \tanh (\mathrm{S})+1\right] \\
& \times \mathrm{k}_{\mathrm{DMA}_{\text {ext }}} \times\left(\mathrm{DMA}^{\mathrm{III}}\right)_{\mathrm{int}}
\end{aligned}
$$

where, $\mathrm{V}_{\max _{\mathrm{t}_{1}}}, \mathrm{~K}_{\mathrm{m}_{\mathrm{t}_{1}}}$ and $\mathrm{V}_{\max _{\mathrm{t}_{2}}}, \mathrm{~K}_{\mathrm{m}_{\mathrm{t}_{2}}}$ are the Michaelis constants of the biophysical clearance of ATG and MADG, respectively; $\mathrm{k}_{\mathrm{MMA}_{\text {ext }}}$ and $\mathrm{k}_{\mathrm{DMA}_{\text {ext }}}$ are the rate constants of MMA and DMA clearance, respectively; $f_{m}$ and $f_{d}$ are the dimensionless coefficients of clearance of the respective processes affecting the maximal efflux.

The remaining biotransformation reactions include a series of methylation, glutathione conjugation and oxidation reactions [27] (Equations 17-23).

$$
\begin{aligned}
& \frac{\mathrm{d}(\mathrm{ATG})_{\text {int }}}{\mathrm{dt}}=\mathrm{k}_{\mathrm{ATG}_{\text {int }}} \times\left(\mathrm{iAs}^{\mathrm{III}}\right)_{\text {int }}-\mathrm{k}_{{ }_{\text {iAs }}{ }^{\mathrm{III}}{ }_{\text {int }}} \\
& \times(\text { ATG })_{\text {int }}-\text { MADG }_{\text {ui }}-\frac{\mathrm{d}(\mathrm{ATG})_{\mathrm{ext}}}{\mathrm{dt}}
\end{aligned}
$$

$$
\begin{aligned}
\frac{\mathrm{d}\left(M^{\prime} A D G\right)_{i n t}}{\mathrm{dt}} & =\mathrm{MADG}_{\mathrm{ui}} \\
& +\mathrm{k}_{\mathrm{MADG}_{\mathrm{int}}} \times\left(\mathrm{MMA}^{\mathrm{III}}\right)_{\mathrm{int}} \\
& -\mathrm{DMAG}_{\mathrm{ui}}-\mathrm{HD}_{\mathrm{m}}-\frac{\mathrm{d}(\mathrm{MADG})_{\mathrm{ext}}}{\mathrm{dt}}
\end{aligned}
$$

$$
\begin{aligned}
& \frac{\mathrm{d}\left(\mathrm{MMA}^{\mathrm{III}}\right)_{\text {int }}}{\mathrm{dt}}=\mathrm{HD}_{\mathrm{m}}-\left(\mathrm{k}_{\mathrm{MADG}_{\text {int }}}+\mathrm{k}_{\mathrm{oxm}}\right) \\
& \times\left(\mathrm{MMA}^{\mathrm{III}}\right)_{\mathrm{int}}-\frac{\mathrm{d}\left(\mathrm{MMA}^{\mathrm{III}}\right)_{\mathrm{ext}}}{\mathrm{dt}}
\end{aligned}
$$

$$
\begin{aligned}
& \frac{\mathrm{d}\left(\mathrm{MMA}^{\mathrm{V}}\right)_{\text {int }}}{\mathrm{dt}}=\mathrm{k}_{\text {oxm }} \times\left(\mathrm{MMA}^{\mathrm{III}}\right)_{\text {int }} \\
& -\frac{\mathrm{d}\left(\mathrm{MMA}^{\mathrm{V}}\right)_{\text {ext }}}{\mathrm{dt}}
\end{aligned}
$$




$$
\begin{aligned}
& \frac{\mathrm{d}(\mathrm{DMAG})}{\mathrm{dt}}=\mathrm{DMAG}_{\mathrm{ui}}+\mathrm{k}_{\mathrm{DMAG}} \\
& \times\left(\mathrm{DMA}^{\mathrm{III}}\right)_{\text {int }}-\mathrm{HD}_{\mathrm{d}} \\
& \frac{\mathrm{d}\left(\mathrm{DMA}^{\mathrm{III}}\right)_{\text {int }}}{\mathrm{dt}}=\mathrm{HD}_{\mathrm{d}}-\left(\mathrm{k}_{\text {DMAG }}+\mathrm{k}_{\text {oxd }}\right) \\
& \times\left(\mathrm{DMA}^{\mathrm{III}}\right)_{\text {int }}-\frac{\mathrm{d}(\mathrm{DMA})^{\mathrm{III}} \text { ext }}{\mathrm{dt}} \\
& \frac{\mathrm{d}\left(\mathrm{DMA}^{\mathrm{V}}\right)_{\text {int }}}{\mathrm{dt}}=\mathrm{k}_{\text {oxd }} \times\left(\mathrm{DMA}^{\mathrm{III}}\right)_{\text {int }} \\
& -\frac{d(D M A)^{V} \text { ext }}{d t}
\end{aligned}
$$

where $\mathrm{k}_{\mathrm{MADG}_{\text {int }}}$ is the rate constant of MADG production catalyzed by the Glutathione S-Transferase (GST) family of enzymes; $k_{\text {oxm }}$ is the rate constant for MMA $^{\text {III }}$ oxidation; $k_{\text {DMAG }}$ is the rate constant for DMAG production catalyzed by the Glutathione S-Transferase (GST) family of enzymes and $k_{\text {oxd }}$ is the rate constant for $\mathrm{DMA}^{\mathrm{III}}$ oxidation. It has been suggested for this biotransformation pathway that trivalent arsenicals mostly bound to thiol-containing proteins are conjugated with GSH and methylated in the presence of arsenic methyltransferase (AS3MT) [28]. Therefore, the parameters $\mathrm{k}_{\mathrm{ATGint}}, \mathrm{k}_{\mathrm{MADG}_{\text {int }}}$ and $\mathrm{k}_{\mathrm{DMAG}}$ indirectly represent the binding of trivalent arsenicals to thiolcontaining proteins in the TK model.

The TK model has been implemented in MATLAB; the system of ODEs comprising the TK model is solved numerically using the stiff solver ode15s. First, the model parameters corresponding to low doses (i.e. below the threshold) were estimated using time course in vitro measurements of arsenicals following exposures to $0.1 \mu \mathrm{M}$ iAs ${ }^{\mathrm{III}}$, from Styblo et al. [51]; it was assumed that at this dose, the hepatocytes exhibit no induced antioxidant response. Subsequently, model parameters corresponding to a wider range of doses (i.e. including both low-dose and high-dose behavior) were estimated using dose-response data (for doses ranging from $0.1-10 \mu \mathrm{M}$ ) reported by Drobna et al. [53]. The Drobna dataset includes measured concentrations of iAs ${ }^{\mathrm{III}}$, MMA, and DMA in primary cultured human hepatocytes after $24 \mathrm{~h}$ exposure to iAs ${ }^{\mathrm{III}}$ (data for hepatocytes from 8 donors). For this case study, data on hepatocytes from one donor (white female, aged in the $60 \mathrm{~s}$, Donor C) [53] were used, since this donor had similar characteristics to the human donor in the study by Styblo et al. [51]. The deterministic optimization function fmincon was used for parameter estimation in both cases.

\section{Sensitivity analysis}

Sensitivity analysis provides estimates of how variation of model's output can be apportioned to different sources of variation in model parameters. This quantity is given by the formula:

$$
\frac{\operatorname{var}_{\mathrm{P}}[\mathrm{E}(\mathrm{Y} / \mathrm{P})]}{\operatorname{var}(\mathrm{Y})}=\frac{\mathrm{D}_{\mathrm{P}}}{\mathrm{D}}
$$

where $\mathrm{Y}$ denotes model output and $\mathrm{P}$ denotes the vector of model parameters; $D_{P}$ and $D$ illustrate the partial and total variance of the model output due to variation in model parameters according to assigned statistical distributions.

The Fourier Amplitude Sensitivity Test (FAST) decomposes the total variance of model output (D) into terms of increasing dimensionality. FAST computes the Total Sensitivity Indices (TSI), which account not only for the variance due to individual parameters $\left(D_{i}\right)$, but also estimate the variance due to interaction among parameters $\left(D_{i j}, D_{i j k}\right.$, etc.) The total variance for $n$ dimensions is given by

$$
D=\sum_{i=1}^{n} D_{i}+\sum_{i=1}^{n} \sum_{j=i+1}^{n} D_{i j}+\ldots+D_{1,2, . ., n}
$$

The model parameters were assumed to be normally distributed with a coefficient of variation up to $10 \%$; for some parameters, the coefficient of variation was $1 \%$. Ten thousand $(10,000)$ samples were generated and the normal distributions for all parameters were truncated at $1 \%$ and 99\% (approximately three standard deviations from the mean value). Three model outputs were selected for the sensitivity analysis: Areas under the Curve (AUCs) of total retention of MMA, DMA and iAs ${ }^{\mathrm{III}}$ in human hepatocytes. The SIMLAB modeling platform [54] was used to perform the global sensitivity analysis.

\section{Comparison with the TK modeling formulation for rat hepatocytes}

The TK model presented here was also compared with results from a published model for rat hepatocytes, in order to assess the inter-species differences and the feasibility of direct, cross-species extrapolation. Specifically, the comparison focused on major intracellular processes that influence the different metabolizing rates between these two species. First, the TK modeling formulation of Easterling et al. [34] was parameterized using data from Styblo et al. [51]. Although, a direct comparison is not 
possible because of major differences in model structures, a subset of parameters was selected for comparison that describe three major biochemical processes which account for similar cellular phenomena in both models. These processes include transport of arsenite across cellular membrane, methylation of arsenic, and biotransformation of AS3MT substrate (iAs in the rat model, and ATG in human TK model). Specific parameters used in comparison include (a) normalized activity of AQP9 (NP), which is defined as the ratio of influx and efflux of arsenite, (b) normalized activity of AS3MT $(\mathrm{NM})$, which is defined as the ratio of the corresponding reaction parameters, and (c) bioavailability of AS3MT substrate (BMRS), which is defined as the ratio of rates of hydrolysis and conjugation of iAs for the human model, and the dissociation constant for the protein binding of arsenic in the rat model. These parameters are specified by Equation 26, and are described in Table 2. Parameters governing the efflux of arsenic were not compared because there is no direct correspondence between the modeling formulations.

In order to facilitate direct comparison, approximate volumes of the cell cultures used in different experiments (per well) were estimated. Hepatocytes were assumed to have a spherical shape with $25 \mu \mathrm{m}$ diameter for both humans and rats [55]. Cellular volumes (Volc) for human and rat were estimated to be 1.6 and $0.8 \mu \mathrm{L}$ respectively, based on the number of cells used in human hepatocytes experiments $\left(2^{*} 10^{5}\right)$ and rat hepatocytes experiments $\left(10^{5}\right)[34,51]$.

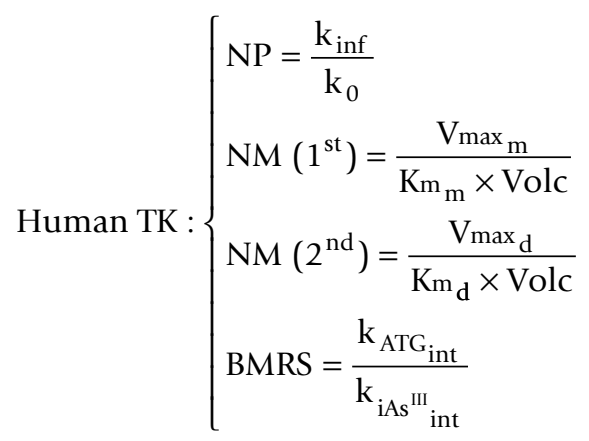

$$
\text { Rat TK: }\left\{\begin{array}{l}
\mathrm{NP}=\frac{\mathrm{T}_{\max }}{\mathrm{K}_{\mathrm{t}} \times \text { Volc } \times \mathrm{p}_{1}} \\
\mathrm{NM}\left(1^{\text {st }}\right)=\mathrm{k}_{3} \\
\mathrm{NM}\left(2^{\text {nd }}\right)=\frac{\mathrm{V}_{\max }}{\mathrm{K}_{\mathrm{m}} \times \text { Volc }} \\
\mathrm{BMRS}=\frac{\mathrm{k}_{2}}{\mathrm{k}_{1}}
\end{array}\right.
$$

Table 2 Comparison of selected parameter values between two hepatocyte-level TK modeling formulations

\begin{tabular}{ccc}
\hline Kinetic Process & $\begin{array}{c}\text { Human-Hepatocyte } \\
\text { TK model }\end{array}$ & $\begin{array}{c}\text { Rat-Hepatocyte } \\
\text { TK model }\end{array}$ \\
\hline $\mathrm{NP}-\mathrm{iAs} \mathrm{SI}^{\mathrm{II}}$ & 0.38 & 0.38 \\
\hline $\mathrm{NM}-1^{\text {st }}$ Reaction (1/min) & 3.35 & 0.02 \\
\hline $\mathrm{NM}-2^{\text {nd }}$ Reaction (1/min) & 147.06 & 0.17 \\
\hline Biotransformation - $1^{\text {st }}$ MRS & 0.0008 & 33.33 \\
\hline
\end{tabular}

The two formulations are developed based on data of arsenic uptake and biotransformation in human and rat hepatocytes (NP: Normalized AQP9 activity, NM: Normalized AS3MT activity, MRS: Methylation Reaction Substrate).

\section{Results and Discussion}

The semi-mechanistic TK model was parameterized using the fmincon function in MATLAB and time course data of arsenicals in human hepatocytes from Styblo et al. [51]. The parameters are shown in Table 1. The model was able to capture the three distinct modes of the time course patterns corresponding to experimental data (shown in Figure 4, Row 1). In contrast, the only currently existing cellular level TK model for arsenic, from Easterling et al. [34], was parameterized using the same optimization technique and data, but the model was not able to adequately capture these modes (shown in Figure 4, Row 2).

The time-course estimates from the TK model show that initially (within first minutes of exposure) the rate of influx of AQP9s is substantially higher than the metabolism, thus leading to a fast accumulation of arsenite inside the cells. Then, the influx is reduced, and metabolism increases, thus leading to a slow decrease in arsenite levels (till 8 to 9 hours). During this period, MMA production appears to be the dominant process, as shown by higher levels of MMA compared to DMA, attributable to the high rate of MADG hydrolysis. Subsequently, the arsenite concentrations decrease at a faster rate, the second methylation reaction becomes more significant, and MADG hydrolysis is inhibited (Equation 9).

Figure 5 shows the dose-response profiles estimated by the TK model parameterized using Drobna et al. data [53]. The model explained the dose-response profiles in the data, and captured the significant decrease in DMA amounts at higher arsenite doses. Based on the sensitivity testing the threshold concentration value of $0.1 \mu \mathrm{M}$ was able to adequately explain the arsenicals retention and metabolism, as shown in Figure 6. Threshold values above $0.1 \mu \mathrm{M}$ overestimate the concentration of DMA in hepatocytes by one order of magnitude in the low dose region. On the other hand, threshold values below $0.1 \mu \mathrm{M}$ (e.g. $0.01 \mu \mathrm{M}$ ) underestimate the DMA concentration substantially.

Results of the sensitivity analysis showed that the relative contribution of variance of individual TK model 


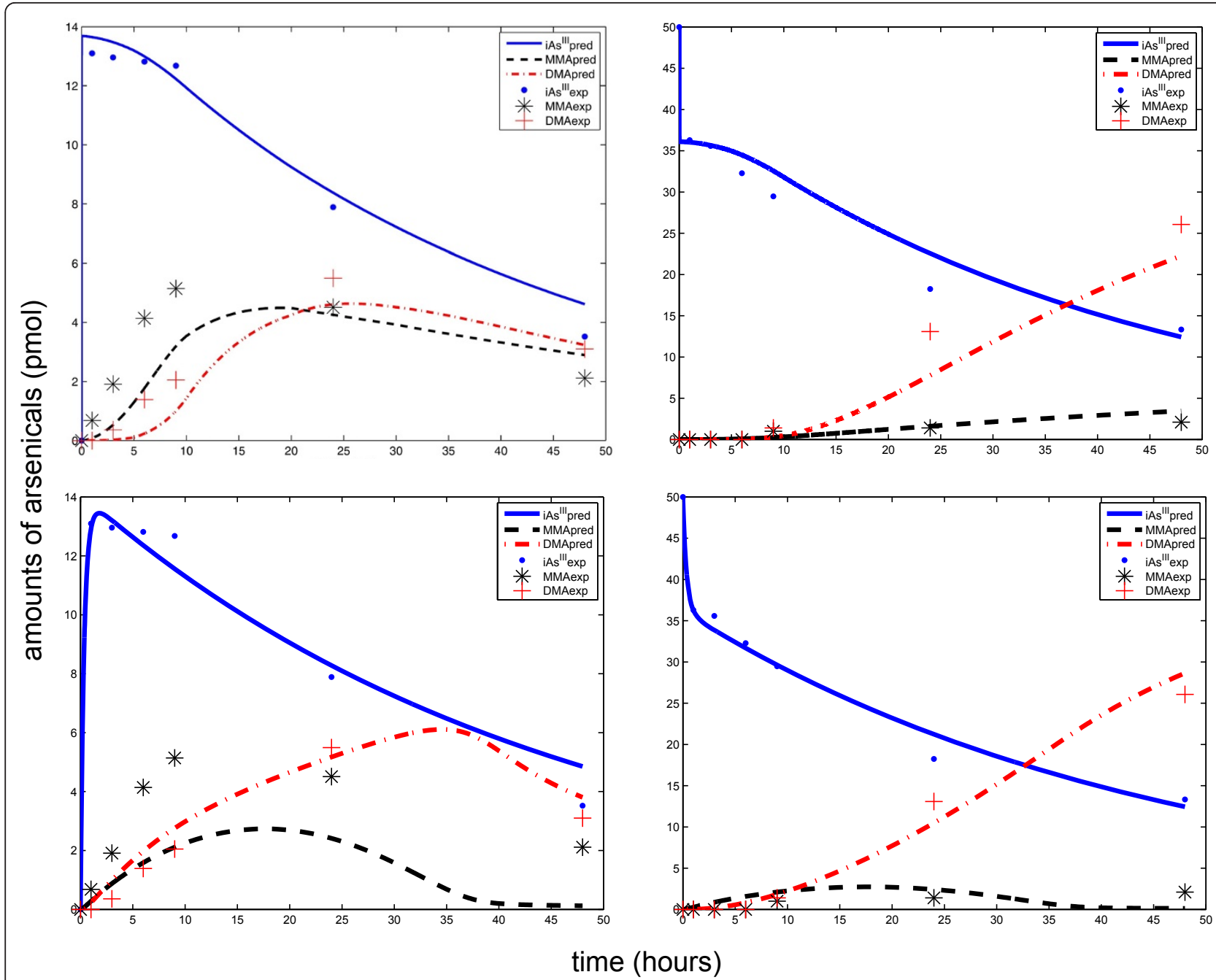

Figure 4 Predicted time course profiles of arsenicals in human hepatocytes using two TK model formulations. The top row shows estimates from the TK model presented here, while the bottom row shows estimates from the TK model formulated using the Easterling et al. [34] approach. The left column shows intracellular levels of iAs'I', total MMA, and total DMA, while the right column shows corresponding extracellular levels. Experimental data are from Styblo et al. [51] (exposures to $0.1 \mu \mathrm{M}$ arsenic for 2 days).

parameters varied significantly across different doses of arsenite. As shown in Figure 7A, at low doses $(0.1 \mu \mathrm{M})$, the transport parameter $\mathrm{k}_{0}$ (Parameter 19) contributes most to the variance in intracellular MMA levels. This agrees with Easterling et al. [34], who reported that the transport parameters are the most significant in relation to intracellular concentration of arsenicals. On the other hand, at higher doses, the parameters related to intracellular biotransformation of MMA are the most influential. For $1 \mu \mathrm{M}$ dose of iAs ${ }^{\mathrm{II}}$ the most significant parameters are $\mathrm{k}_{\text {oxm }}$ (Parameter 5), $\mathrm{f}_{\mathrm{GSH}_{\mathrm{m}}}$ (Parameter 10), $\mathrm{k}_{\text {MMA }}{ }^{\mathrm{III}}$ (Parameter 7) and $\mathrm{K}_{\mathrm{m}_{\mathrm{t}_{2}}}$ (Parameter 15). The first three parameters (Parameters 5, 10, and 7) directly influence oxidation and glutathione conjugation reactions involving $\mathrm{MMA}^{\mathrm{III}}$, whereas the Michaelis constant (Parameter 15) controls the activity of MRPs that efflux MADG from the cells. At high doses, induced antioxidant response of hepatocytes to arsenic leads to increased production of GSH and MRPs in the cells, leading to higher production of MADG, which can be readily effluxed via membrane-associated proteins. On the other hand, when the oxidation reaction is dominant $\left(\mathrm{k}_{\text {oxm }}\right.$; Parameter 5$)$, it results in higher production of $\mathrm{MMA}^{\mathrm{V}}$, which becomes accumulated in the cells, leading to overall increase in intracellular MMA levels.

Figure 7B shows sensitivity analysis results for intracellular DMA levels. Similar to results from sensitivity analysis of MMA levels (Figure 7A), the transport parameter $k_{0}$ (Parameter 19) is the most influential 


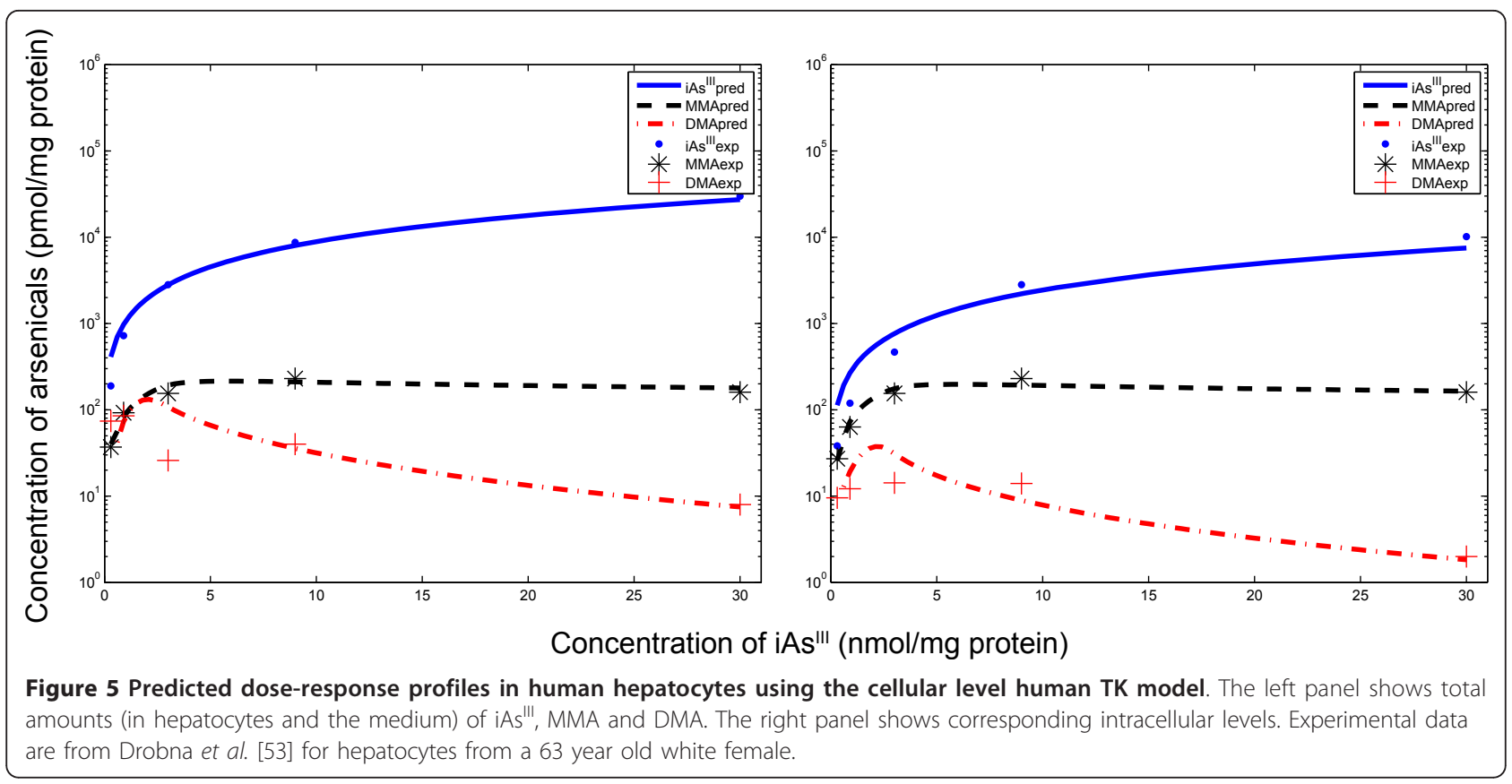

parameter at low doses $(0.1 \mu \mathrm{M})$. For $1 \mu \mathrm{M}$ dose, DMA production is significantly influenced primarily by $\mathrm{f}_{\mathrm{GSH}_{\mathrm{d}}}$ (Parameter 13), which affects the rate of DMAG hydrolysis. Furthermore, the oxidation reaction is not important in the case of DMA levels, because DMA transport across the cellular membrane is much faster compared to MMA transport [56]. This is also corroborated by the relative values of corresponding transport parameters for MMA and DMA $\left(f_{d}>>f_{m}\right.$, as shown in Table 1), and by the findings of Styblo et al. [51].
Figure $7 \mathrm{C}$ shows sensitivity analysis results for intracellular iAs ${ }^{\mathrm{III}}$ levels. At low doses $(0.1 \mu \mathrm{M})$, the TSIs of most parameters are close to 1 , indicating very high contributions. This unusual finding can be attributed to large interaction effects among multiple model parameters on the model output (i.e. binary interactions terms such as $\mathrm{D}_{\mathrm{ij},}$, and tertiary interaction terms such as $D_{i j k}$ ). This was verified by computing first-order sensitivity indices, which account for contribution of each individual parameter $\left(D_{i}\right)$ to the output variance without

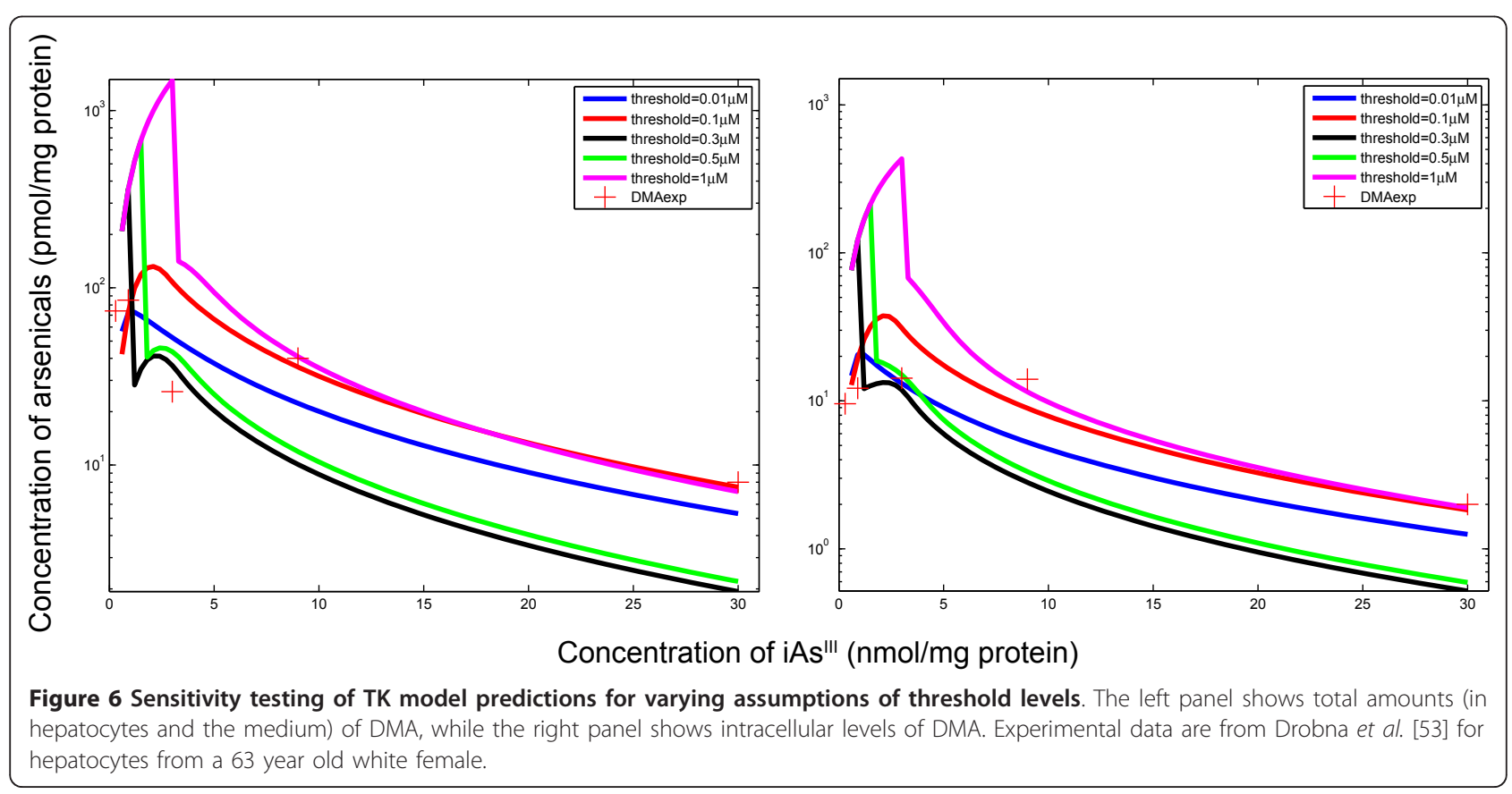


taking into account higher-order interactions $[57,58]$; these indices for all parameters were low $(<0.1)$ at low doses (results not shown). At higher doses, $\mathrm{k}_{\mathrm{ATG}_{\text {int }}}$ (Parameter 1) and $\mathrm{k}_{\text {iAs }}{ }_{\text {III }}$ (Parameter 6) are the most influential. Both these parameters correspond to rate constants in the bidirectional reaction of ATG with iAs $^{\text {III }}$ (glutathione conjugation of arsenite and ATG hydrolysis).

A fundamental hypothesis in this modeling formulation that allows the capturing of the dose-response profiles of arsenic retention and methylation across doses (Figure 5), is the introduction of threshold-dependent non-linear ("switch-like") mechanisms in the metabolic network due to oxidative stress (TR inactivation). This assumption is based on findings that signaling motifs exhibit biological switches under a narrow range of endogenous or exogenous stimuli [59]. This is often described by a Hill equation with a large Hill coefficient (e.g., kinase cascades [60] and nuclear-receptor pathways $[61,62])$. The large Hill coefficient for inhibition of MADG hydrolysis (Table 1 - Parameter 8) points to potential "switch-like" behavior of the activation of Nrf2 due to arsenic-mediated oxidative stress [32].

The parametric comparison between human and rat hepatocyte TK models for arsenic, presented in Table 2, provides insight into factors that affect arsenic metabolism in hepatocytes. Specifically, the AS3MT activity is found to be not a significant factor. Rats have been reported to be much faster metabolizers of arsenic than humans [51], but based on this study this is attributed to other factors. Specifically, in the rat-hepatocyte TK model (Figure 1), the protein-bound arsenite (p-iAs) is biotransformed to iAs (substrate of methylation reaction) at a much higher rate (five orders of magnitude) compared to the biotransformation of iAs ${ }^{\text {III }}$ to ATG (substrate of methylation reaction) of the humanhepatocyte TK model (Figure 3 ). This variability could be influenced by polymorphisms related to GSH production in hepatocytes [63] or availability of thiol-containing proteins to interact with AS3MT [28].

This work demonstrates the development of a prototype semi-mechanistic toxicokinetic (TK) model for arsenicals in human hepatocytes introducing features such as cooperativity and "switch-like" antioxidant response. Even though this model is not directly applicable to in vivo systems as a standalone formulation, it can be applied to inform macroscopic metabolismrelated parameters in the PBTK model. On the other hand, more experimental studies on arsenicals in human hepatocytes will substantially improve model structure and can help in characterizing inter-individual variability in arsenic metabolism. Currently, the Styblo et al. study [51] is the only study in the authors' knowledge that reports time course profiles of arsenic methylation in human hepatocytes. Furthermore, significant uncertainties exist in experimental data due to the limitations of widely used techniques such as hydride generationatomic absorption spectroscopy (HG-AAS) and high performance liquid chromatography-inductively coupled plasma-mass spectrometry (HPLC-ICP-MS), where glutathione conjugated arsenic species ATG and MADG have been reported to be degraded to iAs ${ }^{\mathrm{II}}$ and $\mathrm{MMA}^{\mathrm{III}}$ during the speciation analysis in the bile of rats exposed to arsenic $[64,65]$.

This cellular-level TK model is based on an arsenic biotransformation pathway where arsenic-GSH adducts (ATG, MADG) are substrates for the respective 
methylation reactions $[27,28]$. It should be pointed out that arsenic can be efficiently methylated even in the absence of GSH $[49,66]$, indicating that arsenic-GSH complexes need not be major species in the methylation of arsenic. On the other hand, the explicit consideration of arsenic-GSH complexes allows the description of a hysteresis behavior associated with methylation reactions and the stimulating role of GSH in these processes (Equations 7-8); so, this mechanism has been selected in this model. It should be noted that it is beyond the scope of this manuscript to comparatively evaluate the different arsenic biotransformation mechanisms.

Clearly it is, in principle, possible to incorporate into this cellular level TK model both the oxidative and reductive mechanisms as individual pathways. However, currently available experimental data are not adequate for estimating the relative contributions of each pathway. Development of improved experimental techniques for quantifying binding of arsenicals to GSH and thiolcontaining proteins will allow the estimation of the relative contribution of each pathway. Since AS3MT coexists in hepatocytes with a number of competing elements that affect its action, its activity should be determined based on the availability of each of these elements. For instance, to study the effectiveness of the oxidative mechanism, it is possible to knock out GSH biosynthesis in hepatocytes by interfering with the activity of Glutamate-Cysteine Ligase (GCL) [67], and exposing them to various doses of arsenite. Such data sets can be used to estimate AS3MT activities along the two competing reaction pathways; this type of information is necessary in order to extend the mathematical formulation of the model described here to include both competing methylation pathways.

Parameter identification is an important issue in computational biology since most of the models involve more parameters than the available data. The TK model was parameterized using data on total arsenic of three species (iAs, MMA, DMA) and it was able to capture the modes of arsenic retention and methylation in human hepatocytes, but was not able to exactly capture the time-course profiles from the experimental data. In order to reduce the uncertainty associated with this issue, sensitivity analysis and testing were conducted as a means to identify the relative impact of each parameter on model predictions [68]. Additional time-course data (either on intermediate species or under more exposure/dose conditions) can improve model performance, and can help obtain additional mechanistic insights into the dynamics of arsenicals in hepatocytes.

\section{Conclusions}

A cellular-level TK model was developed based on a recently proposed pathway of arsenic biotransformation.
This model can describe uptake, retention and clearance of arsenicals in human hepatocytes using a semimechanistic approach. It highlights the key biological processes that influence arsenic metabolism by explicitly modelling the metabolic network of GSH-adducts formation [27]. Moreover, comparison of the model structure and parameters with a rat-hepatocyte TK model [34] highlights the relative roles of different metabolic reactions in the methylation of arsenic. Ongoing work involves incorporating this cellular-level semi-mechanistic TK model as a module within a whole-body PBTK model of arsenic [44], in order to improve the PBTK model parameterization and its predictions [69].

\section{Acknowledgements}

This work was primarily supported by the USEPA-funded Environmental Bioinformatics and Computational Toxicology Center (ebCTC), Grant \# GAD R 832721-010. Additional support was provided by the NIEHS sponsored UMDNJ Center for Environmental Exposures and Disease, Grant \#: NIEHS P30ES005022.

\section{Author details}

'Environmental and Occupational Health Sciences Institute (EOHSI) a joint institute of UMDNJ-Robert Wood Johnson Medical School and Rutgers University 170 Frelinghuysen Rd, Piscataway, NJ 08854 USA. ${ }^{2}$ Department of Biomedical Engineering, Rutgers University 599 Taylor Road, Piscataway, NJ 08854 USA.

\section{Authors' contributions}

SKS conceived the study as part of his doctoral dissertation, developed and implemented the mathematical model, analyzed the results and drafted the manuscript. CJB and SSI contributed to the development of the

mathematical model, analysis of the results and manuscript drafting. PGG conceived the study and supervised the work. All authors read and approved the manuscript.

Received: 16 February 2010 Accepted: 25 January 2011

Published: 25 January 2011

\section{References}

1. Cullen WR, Reimer KJ: Arsenic Speciation in the Environment. Chemical Reviews 1989, 89:713-764.

2. ATSDR: Toxicological Profile for Arsenic. Atlanta: Agency for Toxic Substances and Disease Registry, US Department of Health and Human Services 2007.

3. Schuhmacher-Wolz U, Dieter HH, Klein D, Schneider K: Oral exposure to inorganic arsenic: evaluation of its carcinogenic and non-carcinogenic effects. Critical Reviews in Toxicology 2009, 39:271-298.

4. Guha Mazumder DN: Chronic arsenic toxicity \& human health. Indian J Med Res 2008, 128:436-447.

5. USEPA: National primary drinking water regulations; arsenic and clarification to compliance and new source contaminants monitoring; final rule. Federal Register 2001, 66:6975-7066.

6. Cohen SM, Arnold LL, Eldan M, Lewis AS, Beck BD: Methylated arsenicals: The implications of metabolism and carcinogenicity studies in rodents to human risk assessment. Critical Reviews in Toxicology 2006, 36:99-133.

7. Vahter M, Marafente E: Reduction and binding of arsenate in marmoset monkeys. Archives of Toxicology 1985, 57:119-124.

8. Tseng $\mathrm{CH}$ : A review on environmental factors regulating arsenic methylation in humans. Toxicology and Applied Pharmacology 2009, 235:338-350.

9. Kligerman $A D$, Tennant AH: Insights into the carcinogenic mode of action of arsenic. Toxicology and Applied Pharmacology 2007, 222:281-288.

10. Dopp E, Hartmann LM, Florea AM, von Recklinghausen U, Pieper R, Shokouhi B, Rettenmeier AW, Hirner AV, Obe G: Uptake of inorganic and organic derivatives of arsenic associated with induced cytotoxic and 
genotoxic effects in Chinese hamster ovary (CHO) cells. Toxicology and Applied Pharmacology 2004, 201:156-165.

11. Dopp E, Hartmann LM, von Recklinghausen U, Florea AM, Rabieh S, Zimmermann U, Shokouhi B, Yadav S, Hirner AV, Rettenmeier AW: Forced uptake of trivalent and pentavalent methylated and inorganic arsenic and its cyto-/genotoxicity in fibroblasts and hepatoma cells. Toxicological Sciences 2005, 87:46-56.

12. Schwerdtle T, Walter I, Mackiw I, Hartwig A: Induction of oxidative DNA damage by arsenite and its trivalent and pentavalent methylated metabolites in cultured human cells and isolated DNA. Carcinogenesis 2003, 24:967-974.

13. Lin S, Del Razo LM, Styblo M, Wang CQ, Cullen WR, Thomas DJ: Arsenicals inhibit thioredoxin reductase in cultured rat hepatocytes. Chemical Research in Toxicology 2001, 14:305-311.

14. Rossman TG: Mechanism of arsenic carcinogenesis: an integrated approach. Mutat Res 2003, 533:37-65.

15. Liu ZJ, Sanchez MA, Jiang X, Boles E, Landfear SM, Rosen BP: Mammalian glucose permease GLUT1 facilitates transport of arsenic trioxide and methylarsonous acid. Biochemical and Biophysical Research Communications 2006, 351:424-430

16. Liu ZJ, Shen J, Carbrey JM, Mukhopadhyay R, Agre P, Rosen BP: Arsenite transport by mammalian aquaglyceroporins AQP7 and AQP9. Proceedings of the National Academy of Sciences of the United States of America 2002, 99:6053-6058.

17. Tsukaguchi H, Weremowicz S, Morton CC, Hediger MA: Functional and molecular characterization of the human neutral solute channel aquaporin-9. American Journal of Physiology-Renal Physiology 1999, 277: F685-F696.

18. Drobna Z, Walton FS, Paul DS, Xing WB, Thomas DJ, Styblo M: Metabolism of arsenic in human liver: the role of membrane transporters. Archives of Toxicology 2010, 84:3-16.

19. Thomas DJ: Molecular processes in cellular arsenic metabolism. Toxicol Appl Pharmacol 2007.

20. Kala SV, Kala G, Prater Cl, Sartorelli AC, Lieberman MW: Formation and urinary excretion of arsenic triglutathione and methylarsenic diglutathione. Chemical Research in Toxicology 2004, 17:243-249.

21. Kala SV, Neely MW, Kala G, Prater Cl, Atwood DW, Rice JS, Lieberman MW: The MRP2/CMOAT transporter and arsenic-glutathione complex formation are required for biliary excretion of arsenic. Journal of Biological Chemistry 2000, 275:33404-33408.

22. Kobayashi Y, Hayakawa T, Hirano S: Expression and activity of arsenic methyltransferase Cyt19 in rat tissues. Environmental Toxicology and Pharmacology 2007, 23:115-120.

23. Vahter $\mathrm{M}$, Concha $\mathrm{G}$, Nermell B: Factors influencing arsenic methylation in humans. Journal of Trace Elements in Experimental Medicine 2000, 13:173-184.

24. Wood TC, Salavagionne OE, Mukherjee B, Wang LW, Klumpp AF, Thomae BA, Eckloff BW, Schaid DJ, Wieben ED, Weinshilboum RM: Human arsenic methyltransferase (AS3MT) pharmacogenetics - Gene resequencing and functional genomics studies. Journal of Biological Chemistry 2006, 281:7364-7373.

25. Drobna Z, Xing WB, Thomas DJ, Styblo M: shRNA silencing of AS3MT expression minimizes arsenic methylation capacity of HepG2 cells. Chemical Research in Toxicology 2006, 19:894-898.

26. Thomas DJ, Waters SB, Styblo M: Elucidating the pathway for arsenic methylation. Toxicology and Applied Pharmacology 2004, 198:319-326.

27. Hayakawa T, Kobayashi Y, Cui X, Hirano S: A new metabolic pathway of arsenite: arsenic-glutathione complexes are substrates for human arsenic methyltransferase Cyt19. Archives of Toxicology 2005, 79:183-191.

28. Naranmandura $H$, Suzuki $N$, Suzuki KT: Trivalent arsenicals are bound to proteins during reductive methylation. Chemical Research in Toxicology 2006, 19:1010-1018.

29. Waters SB, Devesa V, Del Razo LM, Styblo M, Thomas DJ: Endogenous reductants support the catalytic function of recombinant rat Cyt19, an arsenic methyltransferase. Chemical Research in Toxicology 2004, 17:404-409.

30. Kobayashi M, Yamamoto M: Molecular mechanisms activating the Nrf2Keap1 pathway of antioxidant gene regulation. Antioxidants \& Redox Signaling 2005, 7:385-394.
31. Li WG, Kong AN: Molecular Mechanisms of Nrf2-Mediated Antioxidant Response. Molecular Carcinogenesis 2009, 48:91-104.

32. Wang XJ, Sun Z, Chen WM, Li YJ, Villeneuve NF, Zhang DD: Activation of Nrf2 by arsenite and monomethylarsonous acid is independent of Keap1-C151: enhanced Keap1-Cul3 interaction. Toxicology and Applied Pharmacology 2008, 230:383-389.

33. He XQ, Chen MG, Lin GX, Ma Q: Arsenic induces NAD(P)H-quinone oxidoreductase I by disrupting the Nrf2 center dot Keap1 center dot Cul3 complex and recruiting Nrf2 center dot Maf to the antioxidant response element enhancer. Journal of Biological Chemistry 2006, 281:23620-23631.

34. Easterling MR, Styblo M, Evans MV, Kenyon EM: Pharmacokinetic modeling of arsenite uptake and metabolism in hepatocytes - Mechanistic insights and implications for further experiments. Journal of Pharmacokinetics and Pharmacodynamics 2002, 29:207-234.

35. Tyson JJ, Chen KC, Novak B: Sniffers, buzzers, toggles and blinkers: dynamics of regulatory and signaling pathways in the cell. Current Opinion in Cell Biology 2003, 15:221-231.

36. Miao ZF, Chang EE, Tsai FY, Yeh SC, Wu CF, Wu KY, Wang CJ, Tsou TC: Increased aquaglyceroporin 9 expression disrupts arsenic resistance in human lung cancer cells. Toxicology in Vitro 2009, 23:209-216.

37. Hodgkin AL, Huxley AF: A quantitative description of membrane current and its application to conduction and excitation in nerve. J Physiol 1952, 117:500-544

38. Kitchin $\mathrm{KT}$, Wallace $\mathrm{K}$ : The role of protein binding of trivalent arsenicals in arsenic carcinogenesis and toxicity. Journal of Inorganic Biochemistry 2008, 102:532-539.

39. Kitchin KT, Del Razo LM, Brown JL, Anderson WL, Kenyon EM: An integrated pharmacokinetic and pharmacodynamic study of arsenite action. 1. Heme oxygenase induction in rats. Teratogenesis Carcinogenesis and Mutagenesis 1999, 19:385-402.

40. Shinkai Y, Sumi D, Fukami I, Ishii T, Kumagai Y: Sulforaphane, an activator of Nrf2, suppresses cellular accumulation of arsenic and its cytotoxicity in primary mouse hepatocytes. Febs Letters 2006, 580:1771-1774.

41. Vollrath V, Wielandt AM, Iruretagoyena M, Chianale J: Role of Nrf2 in the regulation of the Mrp2 (ABCC2) gene. Biochemical Journal 2006, 395:599-609.

42. Abraham AK, Mager DE, Gao X, Li M, Healy DR, Maurer TS: MechanismBased Pharmacokinetic/Pharmacodynamic Model of Parathyroid Hormone-Calcium Homeostasis in Rats and Humans. Journal of Pharmacology and Experimental Therapeutics 2009, 330:169-178.

43. Sarangapani R, Teeguarden J, Plotzke KP, McKim JM, Andersen ME: Doseresponse modeling of cytochrome P450 induction in rats by octamethylcyclotetrasiloxane. Toxicological Sciences 2002, 67:159-172.

44. El-Masri HA, Kenyon EM: Development of a human physiologically based pharmacokinetic (PBPK) model for inorganic arsenic and its mono- and di-methylated metabolites. J Pharmacokinet Pharmacodyn 2008, 35:31-68.

45. Mann S, Droz PO, Vahter M: A physiologically based pharmacokinetic model for arsenic exposure .2. Validation and application in humans. Toxicology and Applied Pharmacology 1996, 140:471-486.

46. Yu DH: A physiologically based pharmacokinetic model of inorganic arsenic. Regulatory Toxicology and Pharmacology 1999, 29:128-141.

47. Monod J, Wyman J, Changeux JP: On the Nature of Allosteric Transitions: A Plausible Model. J Mol Biol 1965, 12:88-118.

48. Frieden C: Kinetic aspects of regulation of metabolic processes. The hysteretic enzyme concept. J Biol Chem 1970, 245:5788-5799.

49. Thomas DJ: Unraveling Arsenic-EFGlutathione Connections. Toxicological Sciences 2009, 107:309-311.

50. Leslie EM, Haimeur A, Waalkes MP: Arsenic transport by the human multidrug resistance protein 1 (MRP1/ABCC1) - Evidence that a triglutathione conjugate is required. Journal of Biological Chemistry 2004, 279:32700-32708.

51. Styblo M, Del Razo LM, LeCluyse EL, Hamilton GA, Wang CQ, Cullen WR, Thomas DJ: Metabolism of arsenic in primary cultures of human and rat hepatocytes. Chemical Research in Toxicology 1999, 12:560-565.

52. Gutkin BS, Dehaene S, Changeux JP: A neurocomputational hypothesis for nicotine addiction. Proceedings of the National Academy of Sciences of the United States of America 2006, 103:1106-1111.

53. Drobna Z, Waters SB, Walton FS, LeCluyse EL, Thomas DJ, Styblo M: Interindividual variation in the metabolism of arsenic in cultured 
primary human hepatocytes. Toxicology and Applied Pharmacology 2004, 201:166-177.

54. SIMLAB: Simulation Environment for Uncertainty and Sensitivity Analysis, developed by the Joint Research Centre of the European Commission. Version 322009.

55. Weisz OA, Schnaar RL: Hepatocyte Adhesion to Carbohydrate-Derivatized Surfaces .1. Surface-Topography of the Rat Hepatic Lectin. Journal of Cell Biology 1991, 115:485-493.

56. Dopp E, von Recklinghausen U, Hartmann LM, Stueckradt I, Pollok I, Rabieh S, Hao L, Nussler A, Katier C, Hirner AV, Rettenmeier AW: Subcellular distribution of inorganic and methylated arsenic compounds in human urothelial cells and human hepatocytes. Drug Metabolism and Disposition 2008, 36:971-979.

57. Chan K, Saltelli A, Tarantola S: Sensitivity analysis of model output: Variance-based methods make the difference. Proceedings of the 1997 Winter Simulation Conference 1997.

58. Saltelli A, Tarantola S, Chan KPS: A quantitative model-independent method for global sensitivity analysis of model output. Technometrics 1999, 41:39-56.

59. Andersen ME, Yang RSH, French CT, Chubb LS, Dennison JE: Molecular circuits, biological switches, and nonlinear dose-response relationships. Environmental Health Perspectives 2002, 110:971-978.

60. Ferrell JE, Machleder EM: The biochemical basis of an all-or-none cell fate switch in Xenopus oocytes. Science 1998, 280:895-898.

61. Andersen ME, Eklund CR, Mills JJ, Barton HA, Birnbaum LS: A multicompartment geometric model of the liver in relation to regional induction of cytochrome P450s. Toxicology and Applied Pharmacology 1997, 144:135-144

62. Krishna $\mathrm{S}$, Jensen MH, Sneppen K: Minimal model of spiky oscillations in NF-kappa B signaling. Proceedings of the National Academy of Sciences of the United States of America 2006, 103:10840-10845.

63. Ortiz JGM, Opoka R, Kane D, Cartwright IL: Investigating Arsenic Susceptibility from a Genetic Perspective in Drosophila Reveals a Key Role for Glutathione Synthetase. Toxicological Sciences 2009, 107:416-426.

64. Munro KL, Mariana A, Klavins Al, Foster AJ, Lai B, Vogo S, Cai Z, Harris HH, Dillon CT: Microprobe XRF mapping and XAS investigations of the intracellular metabolism of arsenic for understanding arsenic-induced toxicity. Chemical Research in Toxicology 2008, 21:1760-1769.

65. Cui X, Kobayashi Y, Hayakawa T, Hirano S: Arsenic speciation in bile and urine following oral and intravenous exposure to inorganic and organic arsenics in rats. Toxicological Sciences 2004, 82:478-487.

66. Thomas DJ, Li JX, Waters SB, Xing WB, Adair BM, Drobna Z, Devesa V, Styblo M: Arsenic (+3 oxidation state) methyltransferase and the methylation of arsenicals. Experimental Biology and Medicine 2007, 232:3-13.

67. Dalton TP, Chen Y, Schneider SN, Nebert DW, Shertzer HG: Genetically altered mice to evaluate glutathione homeostasis in health and disease. Free Radical Biology and Medicine 2004, 37:1511-1526.

68. Gutenkunst RN, Waterfall JJ, Casey FP, Brown KS, Myers CR, Sethna JP: Universally sloppy parameter sensitivities in systems biology models. Plos Computational Biology 2007, 3:1871-1878.

69. Clewell RA, Clewell HJ: Development and specification of physiologically based pharmacokinetic models for use in risk assessment. Regulatory Toxicology and Pharmacology 2008, 50:129-143.

doi:10.1186/1752-0509-5-16

Cite this article as: Stamatelos et al: Mathematical model of uptake and metabolism of arsenic(III) in human hepatocytes - Incorporation of cellular antioxidant response and threshold-dependent behavior. BMC Systems Biology 2011 5:16.

\section{Submit your next manuscript to BioMed Central and take full advantage of:}

- Convenient online submission

- Thorough peer review

- No space constraints or color figure charges

- Immediate publication on acceptance

- Inclusion in PubMed, CAS, Scopus and Google Scholar

- Research which is freely available for redistribution

Submit your manuscript at www.biomedcentral com/submit 